\title{
Procedural and parametric variability in studies of conditioned suppression
}

\author{
HANK DAVIS and JANET WRIGHT \\ University of Guelph, Guelph, Ontario N1G 2W1, Canada
}

\begin{abstract}
Conditioned suppression is often regarded as an ideal procedure for studying the interaction between operant and Pavlovian conditioning. The present paper surveys the results of 103 conditioned suppression experiments with regard to differences in a number of key procedural and parametric variables (e.g., on- vs. off-baseline training, number of sessions, CS duration, US duration, and intensity). It was concluded that, despite extensive differences in the stimulus arrangements that are in use, the results of the conditioned suppression procedure are remarkably stable: A positively reinforced operant baseline is suppressed during exposure to a signal which precedes an unavoidable aversive event.
\end{abstract}

The conditioned suppression procedure typically consists of superimposing an aversive Pavlovian arrangement (e.g., tone-shock pairing) upon operant behavior maintained by a schedule of positive reinforcement. The procedure, introduced by Estes and Skinner (1941), continues to generate intensive interest among researcher and theoretician alike. Two literature reviews published more than a decade ago (Davis, 1968; Lyon, 1968) surveyed nearly 200 empirical studies, and the number of papers has surely tripled since then. Moreover, because it affords an opportunity to study the interaction between operant and Pavlovian procedures, conditioned suppression has often been the focal point of theoretical debate (e.g., Davis \& Hurwitz, 1977; Rescorla \& Solomon, 1967).

The typical results of exposure to a conditioned suppression procedure are widely known: Operant responding is suppressed during presentation of the conditioned stimulus (CS). The consistency with which this outcome is obtained is actually quite surprising when one considers the variety of stimulus arrangements that are subsumed under the procedural heading "conditioned suppression." Perusal of the literature, as well as conversations with investigators in the area, suggest that individual laboratories vary widely in their approaches to conditioned suppression. This procedural or parametric variability is rarely discussed unless one is confronted with a conditioning failure or some sort of behavioral anomaly. As previously noted, however, neither of these outcomes is very likely.

In order to address the issue of procedural variability, 103 reports of conditioned suppression experiments published between 1958 and 1978 were surveyed. Approximately 50\% were published in the past decade.

The authors thank Harry Hurwitz for his comments on this paper. The research was supported in part by Grant A0673 from the National Research Council of Canada. Reprints may be obtained from Hank Davis, Department of Psychology, University of Guelph, Guelph, Ontario, Canada N1G 2W1.
We included work by as many different investigators and laboratories as possible. All studies in the survey reported "typical" results, that is, suppression to the CS. The most commonly used index of suppression appeared to be an $\mathrm{A} /(\mathrm{A}+\mathrm{B})$ ratio, where $\mathrm{A}$ represents responding during $\mathrm{CS}$ presentations and $\mathrm{B}$ represents some measure of baseline responding or responding during nonprobed portions of the session. The ratio produces values that range from 0 (maximal suppression), through .50 (responding unaffected by the CS), to 1.00 (conditioned acceleration). Most studies reported suppression ratios between 0 and .10 and, typically, below .05 .

The experiments were compared in terms of the following factors: (1) What schedule of reinforcement maintained the operant baseline? (2) Did CS-US experience occur on or off the operant baseline? (3) How many training sessions were given? (4) How long were the experimental sessions? (5) How many CS-US presentations were given per session? (6) How long was the CS? (7) What were the intensity and duration of the US (assuming it was shock)?

The results are described below and summarized in Table 1. Although every conventional schedule of positive reinforcement was represented, by far the most common selection was a variable-interval schedule. In the majority of cases (85\%), exposure to the CS-US pairings occurred "on-line," that is, while the operant reinforcement schedule remained in effect. "Offbaseline" training typically consisted of withdrawing the lever and presenting the Pavlovian procedure in the operant test chamber. In a minority of off-line cases, a different test chamber was used for CS-US trials.

Although most studies reported between 3 and 10 sessions of CS-US exposure (median $=10$ ), we found a considerable range of values. A surprisingly large number of cases (8\%) involved only a single training session, and, in one case, 140 sessions were run. Experimental sessions ranged in length from $10 \mathrm{~min}$ to $3 \mathrm{~h}$, although most fell between 30 and $60 \mathrm{~min}$. 
Table 1

Occurrence of Different Parameter Values in Conditioned Suppression Experiments Expressed as Percentage of Cases Surveyed

\begin{tabular}{|c|c|c|c|c|c|c|c|c|c|c|c|c|c|}
\hline \multicolumn{2}{|c|}{$\begin{array}{l}\text { Baseline Sched- } \\
\text { ule of Rein- } \\
\text { forcement }\end{array}$} & \multicolumn{2}{|c|}{$\mathrm{N}$ of Sessions } & \multicolumn{2}{|c|}{$\begin{array}{l}\text { Session Length } \\
\text { (min) }\end{array}$} & \multicolumn{2}{|c|}{$\begin{array}{l}\mathrm{N} \text { of CS-US } \\
\text { Trials/Session }\end{array}$} & \multicolumn{2}{|c|}{$\begin{array}{l}\text { CS Duration } \\
\text { (sec) }\end{array}$} & \multicolumn{2}{|c|}{$\begin{array}{l}\text { Intensity of Shock } \\
\text { US (mA) for Rats }\end{array}$} & \multicolumn{2}{|c|}{$\begin{array}{c}\text { US Duration } \\
(\mathrm{sec})\end{array}$} \\
\hline Value & $\%$ & Value & $\%$ & Value & $\%$ & Value & $\%$ & Value & $\%$ & Value & $\%$ & Value & $\%$ \\
\hline CRF & 9 & 1 & 8 & 10 & 4 & 1 & 5 & $5-10$ & 10 & $.1-.25$ & 6 & .1 & 2 \\
\hline FR & 7 & 2 & 7 & 15 & 6 & 2 & 6 & $11-20$ & 13 & .3 & 6 & .2 & 11 \\
\hline FI & 3 & $3-9$ & 20 & $20-29$ & 5 & 3 & 12 & 30 & 13 & .4 & 3 & $.25-.45$ & 4 \\
\hline VI & 70 & 10 & 20 & 30 & 10 & 4 & 16 & 45 & 2 & .5 & 21 & .5 & 49 \\
\hline VR & 8 & $11-19$ & 12 & $31-59$ & 16 & 5 & 7 & 60 & 28 & $.6-.75$ & 6 & $.6-.85$ & 4 \\
\hline \multirow[t]{7}{*}{ DRL } & 3 & 20 & 13 & 60 & 26 & 6 & 12 & $61-105$ & 7 & .8 & 8 & 1.0 & 12 \\
\hline & & $21-30$ & 10 & $61-89$ & 6 & $7-9$ & 12 & 120 & 12 & 1.0 & 19 & 1.5 & 2 \\
\hline & & $31-40$ & 6 & $90-119$ & 9 & 10 & 13 & 180 & 9 & $1.1-1.6$ & 12 & 2.0 & 9 \\
\hline & & $41-60$ & 3 & 120 & 15 & $11-19$ & 9 & $240-2100$ & 6 & 2.0 & 13 & $3.0-6.0$ & 6 \\
\hline & & $>60$ & 1 & 180 & 3 & 20 & 4 & & & 3.0 & 4 & 10.0 & 1 \\
\hline & & & & & & 30 & 2 & & & 4.0 & 2 & & \\
\hline & & & & & & $40-60$ & 2 & & & & & & \\
\hline
\end{tabular}

Note-CRF = continuous reinforcement, $F R=$ fixed ratio, $F I=$ fixed interval, $V I=$ variable interval, $V R=$ variable ratio, and $D R L=$ differential reinforcement of low rates.

The number of CS-US presentations per session appeared related to session length and ranged between 1 and 60 , with most cases lying between 3 and 10 (median =6). The duration of the CS in the cases we surveyed ranged from $5 \mathrm{sec}$ to $35 \mathrm{~min}$. The most common values were $60 \mathrm{sec}$ and, to a lesser extent, $30 \mathrm{sec}$. Shock served as the US in the vast majority of cases, and its reported intensity for rats ranged from .1 to $4.0 \mathrm{~mA}$. However, differences in the circuitry of commercial and locally designed shock sources make interexperimental comparisons of current extremely tenuous. One should probably hesitate before comparing those values at the extremes of the distribution, which represent a difference in intensity by a factor of 40 . Current settings between .5 and $1.0 \mathrm{~mA}$ probably represent a range of moderate and effective shock intensities for use with rats in conditioned suppression. Shock duration appeared unrelated to intensity and ranged from .1 through $10 \mathrm{sec}$, with :5 sec by far the most frequently employed value.

This survey indicates that a wide range of procedural techniques are in use. The results may not be surprising if the stimulus parameters to which one is accustomed lie within the reported range. However, the boundary values suggest that relatively extreme procedural conditions still qualify as conditioned suppression and generate characteristic results. Moreover, it is entirely possible that stimulus parameters more extreme than those detected by our survey are in use and are equally effective. Because it is not customary to report conditioning failures, it is also possible that parametric limits to conditioned suppression have already been encountered and remain unreported.

No doubt, we could have asked additional questions. Some of them (e.g., range of species conditioned, type of CS and US employed) have been previously surveyed (Davis, 1968), and there is little reason to believe that the results of that survey would have changed appreciably. In short, conditioned suppression is a single procedure that is really many techniques, spanning a wide range of stimulus arrangements and parameters. Despite such operational differences, the results seem strikingly similar: Operant behavior is suppressed during presentation of a CS that precedes an aversive US. Although the term "robust" is no doubt overused, it does seem to accurately describe conditioned suppression.

\section{REFERENCES}

Davis, H. Conditioned suppression: A survey of the literature. Psychonomic Monograph Supplements, 1968, 2(Whole No. 30), 283-291.

Davis, H., \& Hurwitz, H. M. B. Operant-Pavlovian interactions. Hillsdale, N.J: Erlbaum, 1977.

Estes, W., \& Skinner, B. F. Some quantitative properties of anxiety. Journal of Experimental Psychology, 1941, 29, 390-400.

Lyon, D. O. Conditioned suppression: Operant variables and aversive control. Psychological Record, 1968, 18, 317-338.

Rescorla, R., \& Solomon, R. Two process learning theory: Relationships between Pavlovian conditioning and instrumental learning. Psychological Review, 1967, 74, 151-182.

(Received for publication June 4, 1979.) 